\title{
Military Reports and the Problem with Technological Agency
}

\author{
Victoria L. Sadler
}

Metropolitan State University

À l'aide d'exemples puisés dans le rapport de la mort d'une pilote d'avion à réaction de la marine américaine, cet article démontre à quel point les pratiques d'un groupe sont enchâssées dans un genre dont le registre (Halliday et Martin, 2003) permet le partage des interventions entre humains et entités non humaines. Dans le cadre d'un système sociotechnique comme celui associé aux atterrissages sur un porte-avion, le problème complexe lié au partage des interventions s'ajoute à celui du langage concis et ambigu. Les communicateurs techniques, qui travaillent au sein des organismes gouvernementaux où humains et entités non humaines sont extrêmement interdépendants, sont encouragés à pousser le genre du rapport administratif au point de créer un contexte permettant de comprendre le partage des interventions.

By using examples from the report of the death of a US Navy female jet pilot, this article shows how genre embeds the practices of a community by employing a register (Halliday and Martin 2003) that shifts agency between human and non-human entities. Added to the complex issue of agency in a sociotechnical system such as that of an aircraft carrier landing is dense and ambiguous language. Technical communicators working in governmental organizations in which human and nonhuman are highly interdependent are encouraged to push the report genre to provide a context for understanding the shifting of agency.

On October 25, 1994, US Navy Lieutenant Kara S. Hultgreen was attempting to land her F-14A Tomcat fighter jet on the deck of an aircraft carrier in the Pacific Ocean, about 50 miles west of San Diego, California. The landing was aborted; Hultgreen lost control of the aircraft and then drowned after being ejected from the plane into the ocean. Her radar officer, Lieutenant Matthew P. Klemish, successfully ejected and was rescued from the ocean within minutes; he received minor injuries.

You might hear of an event such as this one and not think twice. After all, accidents occur during military training and during military operations; this is a consequence of military readiness. The military routinely conducts internal investigations of accidents 
and issues reports, but these reports rarely are read by anyone outside of the military. When they are, though, as in Hultgreen's case and more recently in the reports of military investigations related to operations in Iraq (e.g., the Abu Ghraib detention facility, $800^{\text {th }}$ Military Police Brigade, and $205^{\text {th }}$ Military Intelligence Brigade), we can analyze how the practices of a military community are embedded in genre. ${ }^{1}$

This article will examine an important piece of technical communication related to the case, the official US Navy report based on the investigation of Hultgreen's crash. Primarily, I will focus on how the practices of the naval combat aviation community reveal themselves in language that assigns agency to humans and to nonhumans, reflecting the close interdependence of human and nonhuman required to land a fighter jet on an aircraft carrier.

\section{Genre, Situated Cognition, and Communities of Practice}

I view the Navy report as a genre embedded in the community of combat aviation (comprising military aviators; aviation support personnel; legal oversight; and safety regulations). My perspective draws from Rhetorical Genre Studies (RGS; see Artemeva [2004] for a comprehensive overview), particularly as it has been influenced by social theories of learning and practice and how RGS conceptualizes a community of practice. "Each community of practice is constituted by distinct intellectual and social conventions. These conventions are shared assumptions about the roles of the audience and the writer and the social purposes for communicating" (Artemeva, 2004, pp.23-24). Combat aviation is a community of practice (COP), and in this study I look at a slice of that community - the practice of an F-14 pilot landing on an aircraft carrier-recognizing that this COP is supported by many other communities (e.g., legal; safety; maintenance; aeronautics).

I share the view of Berkenkotter \& Huckin (1995) that genre knowledge is sociocognitive, "best conceptualized as a form of situated cognition embedded in disciplinary activities" (p. 3). The F-14 combat aviation community of practice (hereafter CACOP) understood the JAG report and its language because of their "participation in the communicative activities of daily and professional life" (p. 4). This understanding influenced how the authors wrote the report and how readers (both inside and outside of the CACOP) interpreted the Hultgreen report. As Artemeva (2004) notes, RGS should be used in concert with other theories, and I draw on scholarship in organizational performance (Perrow,1984; LaPorte and Consolini,1991); sociology of science and technology (Pickering,1995); and writing studies (Giltrow, 2002; Halliday and Martin,1993) to examine passages from the report and problematize the issue of agency in this genre.

My view is that because members of the CACOP interact with and depend on non-human entities, their language assigns agency to those entities. This becomes a 
problem in a genre whose structure limits an authorial voice and tends to favor the most recent endorsement (explained below as part of the generic structure) as the genre's authoritative voice. The authors of the Hultgreen report are members of the CACOP, whose livelihood depends on close interactions with non-human entities, such as jet aircraft and wind speed and direction, and the authors' stylistic choices reflect these interactions. By examining specific passages from the Hultgreen report, I show how activities of the CACOP's professional lives are embedded in the genre via language, which at critical points shifted agency to non-human entities. I draw on Halliday and Martin (1993) and Giltrow (2002) to show how heavily nominalized, "agentless" writing creates density and ambiguity.

\section{Background on the Case}

Lieutenant Kara Hultgreen was the first woman assigned to a combat aviation position in the US military, and she represented the first step toward fully integrating women into all units of the military. Her death ignited a national debate (which still continues) over the issue of equality for women in the military. ${ }^{2}$ Consequently, there was intense media scrutiny of her case, and the primary focus was on what is called a Judge Advocate General (JAG) report, which is the report of an official accident investigation conducted under the auspices of the Navy's top legal authority, the Judge Advocate General. ${ }^{3}$

Released approximately four months after the crash, the Hultgreen JAG report was controversial because it both absolved Hultgreen of blame for the crash and implied that she was to blame. Critics, both inside and outside of Navy combat aviation, found the announcement to be disingenuous because its conclusion drew on parts of the report whose language obfuscated its own findings. The final paragraph of the basic report both omitted the human agent and shifted agency to non-human entities. "Agentless writing has been condemned as ambiguous and deceptive, an instrument of concealment" and potentially troublesome for readers and writers (Giltrow, 2002, p. 221). Quoting the JAG report, Navy officials announced that a malfunctioning engine, not pilot error, caused the crash. In addition, the majority of JAG reports of similar aviation accidents-reports released within 15 months of the Hultgreen report-did cite pilot error as a cause. ${ }^{4}$

According to the Navy Times, a privately published newspaper read by many members of the Navy, human error had been cited as a factor in $80 \%$ of

F-14 crashes for the 10 years preceding Hultgreen's crash (Garrison, 1995, p.3). In the JAG reports that I examined, pilot error was cited as the cause of two accidents and as a contributing factor in three others (a percentage of 71.4). My point is that unambiguously blaming a pilot for causing or contributing to an accident seemed to be typical and therefore the expected cause of an accident like Hultgreen's. 


\section{Combat Aviation COP}

All of the JAG reports I examined contained written expression of what Berkenkotter (2000) and others call "the scientific habit of mind," a way of thinking and writing that differs from that of non-experts and often impedes communication between expert and non-expert. Scientific discourse contains characteristic features, such as lexical density (the existence of many technical terms and nominalizations) and syntactic ambiguity (when relationships between words in verbal expressions are unclear). Features such as these create a scientific register, described by Halliday and Martin (1993, pp. 86-87) as sociolinguistically appropriate choice of language and of modes of expression. The Hultgreen JAG report exhibited what I call a CACOP register that not only contained features of scientific discourse (i.e., lexical density and syntactic ambiguity) but also implicitly acknowledged the importance of the close interaction of humans with technologies in the practice of combat naval aviation.

A salient feature of the CACOP register was language that either assigned no agency or that shifted agency from human to non-human and back again, reflecting the role of non-human technologies and agents in the combat naval aviation community. The JAG accident report genre reflects what Pickering (1995) called the constitutive intertwining of human and material agency, which is "a very important degree of symmetry and interconnection between human agency and material agency: as respectively disciplined in practice and as captured in machines, they are both repetitive and machinelike and they collaborate in performances" (p.16). Later in this article, I describe aircraft carrier landing operations to more clearly show this constitutive intertwining, and I provide excerpts from the report to show how tacit understanding of this intertwining is revealed in language.

In her discussion of style, Giltrow (2002) explains how linguistic density and ambiguity can create agentless writing in which "doers of action slip away when the actions are turned from nouns to verbs" (p. 221). Agentless writing must also be examined in context to be fully understood; for example, nominalizations may function to show causality instead of to avoid identifying the doers of actions. As Giltrow, drawing on Halliday and Martin (1993) explains, "the action or event stabilized as a noun can then be worked into an arrangement with other named phenomena ...these arrangements, Halliday and Martin argue, are designed to reveal relations of cause" (p. 225).

\section{Intertwining of Human and Material Agency}

Employing sea-based vessels, people, and procedures in support of US government goals, the US Navy operates what Perrow (1984) called tightly-coupled systems. The Hultgreen report describes one example of this type of system: a jet landing on an aircraft carrier. An aircraft carrier is a type of sociotechnical system (i.e., technologies 
inextricably intertwined with people) in which nonhuman agents, at times, are just as important as human agents. The following description of a landing on an aircraft carrier helps to illustrate Pickering's concept of constitutive intertwining:

A recovery cycle [i.e., aircraft landing] is an extraordinary mix of delicate maneuvers, thunder, and careful, concentrated movement of aircraft deck handlers ("yellow shirts") and dozens of watchful eyes intently scanning the deck for any potential misadventure. As each aircraft comes round to the final approach, a television camera picks it up for video recording, and later debriefing. These images are sent round the ship and into squadron spaces on a hundred screens. (LaPorte and Consolini, 1991, p. 38)

As Greg Myers (1996) said about the safety system of a nuclear power plant, the "whole system can be seen as a complex of the human and nonhuman" in which "machines substitute for humans watching, texts substitute for humans directing, [and] organizations speak for individuals" (p. 14). Myers' assessment of the power plant's sociotechnical system can be compared to a jet landing on an aircraft carrier's flight deck. There are people watching the approach, some aided by technologies such as radar and binoculars. There are people watching video monitors, logging data, and exchanging information; in addition, there are cameras watching and automatically recording, seeing aspects of the landing that no human can witness. Both examples-aircraft carrier and power plant--show how humans and nonhumans share agency in sociotechnical organizations, and the JAG report genre reflects this sharing.

Pickering's (1995) concept of constitutive intertwining, mentioned earlier as "a very important degree of symmetry and interconnection between human agency and material agency" (p. 6), includes the word "symmetry," but he does not view humans and nonhumans as symmetrical. That is, his concept does not view humans as completely interchangeable with nonhumans in a sociotechnical network. Instead, Pickering's view (one that I share) is that intentionality, the human capacity to create goals based on future states that don't presently exist (pp. 17-19), makes total symmetry impossible in practice. In an aviation community, human pilots follow repetitive, disciplined procedures that result in flying an airplane; they manipulate the machines, machines manipulate the wind, and all are performing collaboratively. This intertwining manifests itself, not only in the JAG report genre, but also in other genres employed by communities that work closely with technology. When reports describe accidents, especially those involving sociotechnical systems such as aircraft carriers, the reports may also shift agency between human pilot and nonhuman agent (e.g., aircraft equipment, weather, or time). The interdependence of pilot and technologies is crucial to successfully landing on an aircraft carrier and consequently manifests itself in the community's communications, including the JAG report genre. 
This doesn't mean that the Hultgreen JAG report writers were correct in failing to clearly identify Hultgreen's agency, only that this complex interplay of human aviator and nonhuman elements must be understood in order to understand the JAG report genre and to understand the language in Hultgreen's JAG report.

\section{The JAG Report Structure}

The Hultgreen JAG report, as a whole, can be viewed as having two parts: 1) a basic report written by an appointed investigative officer and the enclosures to the basic report, and 2) endorsements, which are added to the basic report in chronological and rank order as they pass up the chain of command.' The basic report comprises only 39 pages, but 78 enclosures (e.g., witness statements; aircraft mishap worksheet; excerpts from F-14A technical operations; Navy aviation maintenance message) bring the total number of pages to approximately 400 . Because the JAG report genre's purpose is to establish whether injury occurred in the line of duty or due to misconduct, it must be reviewed by the servicemember's chain of command. Hultgreen's JAG report first was endorsed by her squadron commander and then made its way up through the carrier air wing, the carrier group, and the naval air force-Pacific Fleet-endorsed by the commanders at each level.

Although the Hultgreen basic report is one unit, it has several parts, which can be considered both separately and as a whole: the investigation's basic results are the foundation upon which are added subsequent endorsements (i.e., responses to the basic report) by four increasingly higher levels of command. Attached to the basic report are the 78 enclosures mentioned above; these are references for the second section (called "Findings of Fact") of the basic report. Because endorsements are placed on top of the basic report and any previous endorsements, the top endorsement is the most recently written. This arrangement privileges hierarchy and rank, because the final (top-most) endorsement will also be from the highest level of command and will be the first read. An endorsement is in the form of a memorandum, usually 1-2 pages long, in which a commander comments on the basic report and on any previous endorsements. These command endorsements are part of the overall JAG accident report but precede the basic report, so I consider them to be separate from the basic report and do not examine them here.

According to the JAG Manual (the directive for conducting JAG investigations, abbreviated as JAGMAN), the investigating officer's responsibility is to provide "consistent findings of fact" based on information that the officer would "search out, develop, assemble, analyze, and record" (JAGMAN 201.b). Preston C. "Clay" Pinson, a Navy officer, conducted the investigation and wrote the 39-page basic report. The Hultgreen basic report follows, in this order, a typical JAG report format:

- List of Enclosures (i.e., Attachments) 
- Preliminary Statement: explains procedures investigating officer (Pinson) followed, and it summarizes the events of the accident ;

- Findings of Fact: based on enclosures, which contain evidence Pinson gathered during the investigation;

- Opinions: Pinson's statements based on Findings of Fact; and

- Recommendations: state actions, punitive or not, that the report's approval authority (the highest level of command) should take.

All of these sections consist of separate, numbered entries, which allow no sustained narrative to be created by the entries. Some of the lengthier entries, particularly Opinion \#23 that I analyze later, recreate some of the actions that occurred at the time of the accident, but as a whole, the basic report is a collection of separate entries instead of a narrative explanation of the events leading up to and including the accident. I will now describe the sections of the JAG basic report.

First is the list of enclosures (attachments), which highlights the intertextuality of this genre. The enclosures contain supporting evidence, such as engineering reports, transcripts of witness interviews, and copies of training records, on which Section Three is based. The report presents a great deal of information (summarized in the basic report and detailed in the $350+$ pages of enclosures) that established the circumstances of the crash, along with the physical and emotional states of the aviators (Hultgreen and Klemish), their training history, and the maintenance history of the aircraft that crashed.

The report's second section, the "Preliminary Statement," contains 14 numbered entries that act as an introduction to the report. Entries 1-10 state the report's purpose and the procedures Pinson followed to conduct his investigation; entries 11-13 summarize the section that follows the Preliminary Statement; and the final entry, 14, is a summary of Hutgreen's crash. There is no conclusion in the Preliminary Statement as to what caused the crash; that is contained in the Opinions section. Section Three, called "Findings of Fact" (a term dictated by the JAG manual), comprises 18-and-onehalf pages ( 88 sequentially numbered items) and establishes that there was a crash of an F-14 aircraft resulting in Hultgreen's death. In addition to implying objectivity and "truth" by identifying these entries as "facts," the report's structure required that each entry be followed by parenthetical references to the enclosures on which each fact was based. The initial 20 findings (of a total 88 ) pertained to the readiness and qualifications of Hultgreen and Klemish (her radar officer who survived), the plane they were in, the aircraft carrier they were landing on, and the people who were guiding them onto the carrier.

The report's format and purpose were themselves mandated in a text, the JAG manual, which is another text in the genre system to which a JAG report belongs. As a genre, a JAG report is highly intertextual, created by and referring to texts, such as 
eyewitness statements, engineering reports, maintenance manuals, aviation Standing Operating Procedures, and flight briefings. It is also intratextual: all entries in the "Findings of Fact" section cite the enclosures as source material, and all "Opinions" parenthetically cite Findings of Fact as their source(s). For example, Opinion \#23 (examined later) in the Hultgreen report cited 44 intratextual sources! Also, the command endorsements that I mentioned earlier build on the basic report and on each other, gaining credibility through intertextual reference and through the ranks of the officers who sign the endorsements.

As Devitt (1991) said in her study of tax accountants, referential intertextuality is "the most obvious kind of interaction among texts. Its significance lies in the manner and function of such reference, for the patterns of reference reflect again the profession's activities and relationships" (p. 342). The genre system to which the JAG accident report belongs reflects activities and relationships of the aviation profession, such as engineering reports from the Navy Safety Center; pilot training records; maintenance records; technical manuals; pre-flight briefings; and statements from flight deck crewmembers. The numerous citations tended to bolster the report's credibility by providing visual cues to the results of the investigation, referring to the $350+$ pages of enclosures as the source of "Findings of Fact" and basing "Opinions" on "Findings of Fact."

\section{Hultgreen JAG Report's Decisive Passage}

Next, I examine Opinion \#23, which I consider to be the most important passage of the basic report, because although it can be read as implying Hultgreen's contributions to the crash, it was most often pointed to as absolving Hultgreen of blame. Opinion \#23 is the final and concluding opinion of the Hultgreen basic report, a passage in which Pinson creates syntactic ambiguity similar to what Halliday and Martin (1993, pp.77-78) find in scientific discourse. The grammatical ambiguities allowed the endorsement authors to focus on what the passage foregrounded (Tomlin) - the engine malfunction and a lack of time-as causing the crash and to downplay what the passage backgrounded: Hultgreen's piloting actions. Giltrow (2002) describes this as "direct[ing] our attention away from some active elements of the thing referred to" (p. 323). In addition, Pinson hedged in Opinion \#23 by using qualifiers, such as "however," "predominantly," "although," "tends," and "if any," which lessened the impact of the Opinion. It also showed the complex interaction among human and non-human factors and how agency shifted among these factors. In Opinion \#23, Pinson said that time and the engine malfunction were primarily to blame for the crash: "evidence tends to support that an engine malfunction occurred at the worst possible time," identifying nonhuman elements (i.e., mechanical failure and time shortage) as causing the accident.

This focus away from Hultgreen's contributions to the crash led to the Hultgreen 
report being called "disingenuous" by members of the CACOP (current and retired). The Navy spokesman said that the stuck engine valve was the root cause, so the publicity then made the crash monocausal, directing attention away from the parts of the report that identified Hultgreen as responsible for the crash. Journalists, for the most part, uncritically reported the official Navy announcement, but journalists who read the report (e.g., Caldwell 1995; Boyer 1995; Chavez 1995) were skeptical. Opinion \#23 implied Hultgreen's contributions to the crash, but the endorsement writers and some journalists overlooked this, pointing instead to the passage as blaming an engine malfunction for the crash. Underlined words and phrases (below) are examples of how Pinson foregrounded non-human causes of the crash and backgrounded human causes of the crash by using nominalizations, noun strings, and the passive voice, thereby creating grammatical ambiguity.

\section{Opinion \#23 (Numbers follow referenced sentences)}

Responsibility of recognizing an engine malfunction rests predominantly with the pilot of an F-14A. 1. However, it cannot be determined what cockpit indications of engine malfunction(s), if any, were available to LT Hultgreen, nor the time at which they might have become available. 2. Furthermore, although responsibility of the mishap rests with the pilot, evidence tends to support that an engine malfunction occurred at the worst possible time, to which dual engine (normal) wave off techniques exacerbated an already demanding single engine wave off scenario. 3 . The LSO call for wave off was extremely timely, but subsequent pilot technique permitted Angle of Attack to increase to a point where rudder effectiveness began to progressively be reduced to nil and departure from controlled flight was imminent. 4. Sideslip due to yaw and asymmetric thrust also became excessive, but the failure to control Angle of Attack led not only to an unacceptably low airspeed, but also led to the loss of rudder due to asymmetric thrust. 5. (Findings of Fact (29), (30), (31), (42), (43), (44), (45), (46), (47), (48), (49), (50), (51), (52), (53), (54), (55), (56), (58), (59), (60), (61), (62), (63), (65), (66), (67), (68), (69), (70), (71), (72), (73), (74), (75), (76), (77), (78), (79), (81), (83), (84), (85), and (86)).

(US Navy, pp. 28-29)

In Halliday and Martin's (1993) view, ambiguities such as those epitomized by Opinion \#23 "arise especially in two places: 1 ) in strings of nouns, leaving inexplicit the semantic relations (mainly transitivity relations) among them; and 2) in the relational verbs, which are often indeterminate and may face both ways (e.g., higher productivity means more supporting services: does 'means' mean 'brings about', 'is brought 
about by, or 'requires'?)" (67). Pinson's sentence structure placed nominalizations and nouns (i.e., cockpit indications, engine malfunction, wave off techniques, wave off scenario, pilot technique, rudder effectiveness, departure from controlled flight, sideslip, and asymmetric thrust) as the subjects of verbs instead of making the pilot (Hultgreen) the subject.

For example, the first noun string in sentence 3 ("dual engine (normal) wave off techniques") makes "techniques" the subject of the verb "exacerbated" instead of making Hultgreen the subject and stating that she performed the techniques required of a dual engine (normal) wave off. Sentences 4 and 5 use the same syntax, using nominalizations as the subjects of verbs: "pilot technique permitted Angle of Attack to increase ..." and "failure to control Angle of Attack led ..." instead of stating that "Hultgreen's piloting technique permitted Angle of Attack to increase ..." and "Hultgreen's failure to control Angle of Attack led ...." This grammar affects the semantics of the entire passage, because Hultgreen's contributions are implied, not directly stated. Hultgreen is the subject of the entire passage and therefore is the one who exacerbated a demanding situation and permitted Angle of Attack to increase, which led to unacceptably low airspeed, loss of rudder effectiveness, and departure from controlled flight (i.e., airplane crash).

Also, in sentences 1 and 3 , Pinson used the nominalization "responsibility" as the subject ("responsibility ... rests with the pilot"), thereby foregrounding the concept of responsibility, but by not making the pilot the subject, he placed her contribution to the crash in the background. In sentence 4 , Pinson's usage of passive voice allowed him to omit the subject of the verb: "rudder effectiveness began to progressively be reduced to nil . . ." Instead of forcefully stating that pilots were responsible for recognizing engine malfunctions, the excerpt implied that this is not true in all cases, because there are times, such as in Hultgreen's case, when someone or something else (unnamed) besides the pilot has this responsibility. The excerpt also avoided placing responsibility for the mishap with the pilot by mentioning, in sentence 3 , "evidence" that then focused the reader on a nonhuman agent--time--and away from a human agent: the pilot.

I am not suggesting that Pinson should have stated that Hultgreen caused the crash, only that he grammatically and syntactically buried ("backgrounded") her contribution to the crash. I do suggest, however, that he could have foregrounded Hultgreen's role and written Opinion 23 as follows:

\section{Possible Revision of Opinion \#23}

As the pilot, LT Hultgreen was primarily responsible for recognizing an engine malfunction 1. However, I cannot determine what information LT 
Hultgreen had about the aircraft's engine malfunction or when she had any information. 2. Furthermore, although LT Hultgreen was responsible for the mishap, an engine malfunctioned as she was following dual engine (normal) wave off techniques instead of a single engine wave off scenario, and this exacerbated the wave off scenario 3. The LSO call for wave off was extremely timely, but LT Hultgreen's subsequent piloting permitted Angle of Attack to increase to a point where rudder effectiveness became nil and departure from controlled flight was imminent. 4. Sideslip due to yaw and asymmetric thrust also became excessive, but LT Hultgreen's failure to control Angle of Attack led not only to an unacceptably low airspeed, but also led to the loss of rudder due to asymmetric thrust. 5 .

This choice of syntax would have made Hultgreen the subject of the passage and placed emphasis on her contribution to the crash, probably lessening the skepticism Navy officials encountered when publicizing the report's findings.

Pinson's linguistic choices resulted in his finding Hultgreen responsible for the crash but not blaming her for the crash. In Opinion \#23, Pinson wrote that Hultgreen did not seem aware of the nature of the aircraft's problem (a single-engine stall) and did not take the necessary corrective action. As discussed above, although Pinson said that "responsibility of the mishap rests with the pilot", he did not clearly state that Hultgreen's actions were a contributing cause of the crash. In Opinion \#23, no human agent bore responsibility or blame, so when the endorsers read the report, they named a stuck engine valve as the cause of the crash.

Textually, this shift of agency to nonhuman elements is most obvious in Opinion \#23. Nominalizations and nouns, such as "cockpit indications," "failure to control," "techniques," and "sideslip," refer to parts of the plane or to Hultgreen's technical actions as a pilot, which are nonhuman elements or agents. Grammatically, the nonhuman elements are active agents, as they "exacerbate," "become excessive," are "reduced to nil," and so on. These grammatically active agents are the focus of attention in this excerpt and take the reader's attention away from the issue of human agency. As I have shown, nonhuman agents are an accepted part of the network of aircraft carrier landings, and their agency is an important feature of the JAG report genre. The first and third sentences of Opinion \#23 ("Responsibility of recognizing an engine malfunction rests predominantly with the pilot of an F-14A . . . Furthermore, although responsibility of the mishap rests with the pilot") place responsibility for the mishap with the pilot, but other parts of the passage dilute these sentences to the point that no human agent is found to have caused the crash. Instead of assigning blame to the human agent with whom "responsibility rests," the report placed blame on nonhuman sources: an engine malfunction and lack of time. 
I return briefly to the endorsements, which generically function as a vehicle for commanding officers to create narrative comments as they respond to the basic report. (Commanders are not obligated to wholly accept or reject the basic report; they may comment as they see fit.) The endorsement writers did use the genre to voice their comments, but because generic convention mandates that the last endorsement written by the highest-ranking officer and was the most recent, it is typically viewed as the authoritative voice. In the Hultgreen JAG report, the endorsements reinforced the investigating officer's focus on nonhuman agents as responsible for the crash, and they backgrounded the human agent's contributions. By using language that focused on non-human agency as causing the crash, the writers essentially ignored the pilot's role in the crash.

\section{Conclusion}

In this article, I have shown how "writers acquire and strategically deploy genre knowledge as they participate in their field's or profession's knowledge-producing activities" (Berkenkotter and Huckin, 1995, p.3). I described the JAG aircraft accident report genre as instantiating the sociotechnical system of aircraft carrier landings that is the "bread and butter" of Navy combat aviation. Using the "language of the expert" (Halliday and Martin 2003), the Hultgreen report writers deployed their knowledge of naval combat aviation and created more knowledge through their writing. Implicit in the genre is what Andrew Pickering (1995) called constitutive intertwining, which occurs when humans act like machines and machines act like humans and creates a complex "dance of agency" (pp. 21-22). This intertwining manifested itself in the Hultgreen report through language that shifted action among human and nonhuman factors, but the language didn't carry through and place equal responsibility with both human and nonhuman factors. Instead, the language omitted references to the human factor (i.e., the pilot) and implicated a nonhuman engine valve as the primary cause of the crash.

Technical communicators working in governmental organizations may write, edit, or evaluate accident reports similar to that of the Hultgreen JAG report, in which the constitutive intertwining (Pickering 1995) of human and nonhuman is integral. Reports whose language not only reflects the intertwining but also seems to hide the human cause of an accident become problematic and may reflect negatively on the organization that created them. To avoid problems such as these, communicators should advocate for report genres that provide a context for the rapid and complex shifting of agency such as what occurs when an aircraft lands on a carrier. 


\section{References}

Berkenkotter, C. (200o). Scientific writing and scientific thinking: Writing the scientific habit of mind. In M. D. Goggin (Ed.), Inventing a discipline: Rhetorical scholarship in honor of Richard E. Young. (pp. 270-292). Urbana, IL: NCTE.

Berkenkotter, C., \& Huckin, T. N. (1995). Genre knowledge in disciplinary communication: Cognition/culture/power. Hillsdale, New Jersey: Lawrence Erlbaum.

Boyer, P. J. (1995, September 16). Admiral Boorda's War. New Yorker, 60-76.

Caldwell, R. J. Hultgreen case puts the Navy's credibility at risk again. (1995, March 26). San Diego Union-Tribune, p. G1.

Chavez, L. Did Navy policy cost pilot her life? (1995, May 10). USA Today, p. A13.

Devitt, A. J. (1991). Intertextuality in tax acounting: Generic, referential, and functional. In C Bazerman \& J. Paradis (Eds.), Textual dynamics of the professions: Historical and contemporary studies of writing in professional communities. (pp. 336-357). Madison: U of Wisconsin P.

Garrison, B. What killed Hultgreen? (1995, March 13). Army Times, p. 3.

Giltrow, Janet. (2002). Academic writing: Writing and reading in the disciplines, $3^{\text {rd }}$ ed. Ontario: Broadview Press.

Halliday, M.A.K. \& Martin, J.R. (1993). Writing science: Literacy and discursive power. Pittsburgh: $U$ of Pittsburgh P.

La Porte, T. R., \& Consolini, P. M. (1991). Working in practice but not in theory: Theoretical challenges of high-reliability organizations. Journal of Public Administration Research and Theory, 1, 19-47.

Myers, G. (1996). Out of the laboratory and down to the bay: Writing in science and techology studies. Written Communication, 13, 5-43.

Perrow, Charles. (1984). Normal accidents: Living with high-risk technologies. New York: Basic Books.

Pickering, A. (1995). The mangle of practice: Time, agency, and science. Chicago: $\mathrm{U}$ of Chicago P.

Sadler, Victoria L. (2003) Rhetoric, technology, and the military: The death of a "topgun" (Doctoral dissertation, University of Minnesota, 2003). Dissertation Abstracts International, 64, $11 \mathrm{~A}$.

Tomlin, Russell S. (1985). Foreground-background information and the syntax of subordination. Text, 5, 85-122. 


\section{United States Department of the Navy. (1995). Investigation into the VF-213 F-14A aircraft accident on 25 October 1994 that resulted in the death of Lieutenant Kara S. Hultgreen, USN, 450-59-6806/1310 and injury of Lieutenant Matthew P. Klemish, USN,/1320. Washington, DC: Office of the Navy Judge Advocate General.}

\section{Endnotes}

1 See the Autumn 2004 issue of this journal for an overview by Natasha Artemeva of the current field of Rhetorical Genre Studies (RGS). As Artemeva notes, RGS should be used in concert with other theories, and I draw on scholarship in organizational theory (Perrow); political theory (LaPorte); and sociology of science and technology (Pickering) to discuss the issue of agency in genre. My study of the Hultgreen report finds genre knowledge embedded in and influenced by the professional activities of combat aviation aircraft carrier operations.

2 The Hultgreen case is interesting to study from the perspectives of gender, technology, crisis management, and legal systems, in addition to studying its textual artifacts from a technical communication perspective. (See Sadler 2003 for a more comprehensive analysis of the case.)

3 I refer to the official Navy report as the JAG report, meaning that it is the report of Hultgreen's crash written in accordance with Chapters II, VIII, and IX of the Manual of the Judge Advocate General, US Navy. The Navy refers to this report as a JAGMAN, meaning that it is a report of an investigation prescribed by the JAG manual (JAG Inst 5800.7D 3 October 2000). Other incidents involving loss of life, property damage, or anticipated litigation may be the subject of a JAGMAN investigation. In addition, the Navy typically appoints an Aircraft Mishap Board to conduct a separate investigation into aircraft incidents. The report of this investigation, referred to as a Mishap Investigation Report (MIR), is "privileged information" not officially released to the public, although Hultgreen's MIR was leaked to the Navy Times (a private newspaper) and therefore available in an unofficial format. I focus on the JAG report because of its official status.

4 I examined JAG reports of the seven reported similar aircraft accidents occurring from November 1994 through January 1996. Four of those reports clearly stated pilot error as causing or greatly contributing to the accident, and the other three cited equipment failure or maintenance error as causes and clearly exonerated the pilot. In all of these reports, the basic report and the endorsements used direct language (often citing the pilot by name) to establish cause for the accident.

5 In the JAG accident report genre, endorsements are the narrative comments written by commanders and added (in chronological order) as the basic report moves up the chain of command. This means that there are as many endorsements as there are endorsers, and these comments can differ in perspective from each other and from the basic report. Endorsements constitute official acceptance of the basic report, and the command authority of their authors lends them great credibility. Also, endorsements are written after the basic JAG report but placed on top of the report, so readers encounter them first. They contain little technical language and are easier to comprehend, so they typically are the only part of the entire report that much of the audience thoroughly reads. 